\title{
The analysis of output voltage distortion of inverter for frequency lower than the nominal
}

\author{
Jacek Bartman *
}

\begin{abstract}
The paper discussed the studies related to the output voltage distortion of frequency inverter depending on its frequency. The changes in the effective value of voltage, THD, harmonics and interharmonics were presented for three different frequencies, lower than $50 \mathrm{~Hz}$. Additionally, it was shown how these values change depending on measurement time, presenting waveforms cycle by cycle in graphs, averaged in 10 periods and averaged in 150 periods of the analyzed signal. The studies were conducted in the laboratory area equipped with power quality meter class A.

K e y w o r d s: distorted signals, harmonics, interharmonics, THD, RMS, norms
\end{abstract}

\section{Introduction}

Frequency inverter became one of the primary components of most advanced motor drives. Using it for supplying induction motors allows the regulation of their rotational speed and it led to removing an obstacle that impeded their application in motor drives which require the adjustment of rotational speed to user requirements, which caused that induction motors are more widely used [1]. Unfortunately, a receiver that consists of frequency inverter which supplies induction motor is a nonlinear component $[2,3]$. Nonlinearity is mainly caused by the methodology of frequency inverter and particularly by the way of shaping its initial voltage which, as a result, is distorted $[2,3,4]$. It has some regularities, however, they are not repetitive, so it is consequently a nonstationary waveform $[3,5]$ that could be called an almost periodic waveform [6].

The analysis of distorted waveforms is not an easy issue; it involves determining or selecting a number of frequency parameters: primary frequency signal, the number of samples, sampling time and selecting methods and windows for analysis. Investigation of signal distortion gets complicated if it involves, next to harmonics, interharmonics $[2,3,4,7]$. As far as determining and selecting the parameters and methods mentioned before are concerned, non-stationarity and quasi-periodicity entail additional difficulties $[3,5,6]$.

\section{Signal distortion analysis}

Voltage distortion analysis is one of the aspects of assessing the quality of energy $[8,9]$ and is mostly conducted in this context $[10,11,12,13]$. Voltage distortion is the factor which boosts energy consumption and generates additional thermal effects [12, 14], therefore, works are underway with a view to reducing voltage distortion [15], as well as identifying its sources [16]. The basic tool used in the assessment of voltage waveform distortion is the frequency analysis that uses Discrete Fourier Transform (DFT) $[2,4,7]$. An alternative of DFT can be Pronys method [17] or Discrete Wavelet Transform (DWT) [18]. The Pronys method allows precise estimation of frequency and enables to use short analysis windows. DWT allows simultaneous signal presentation in time and frequency domain. However, simplicity and effectiveness encourage to use a fast version of DFT, known as Fast Fourier Transform (FFT). The Fast Fourier Transform signal calculation task reduces to determining of sum numerical values

$$
X_{(k)}=\sum_{n=0}^{N-1} x(n) e^{-j k \frac{2 \pi}{N} n}, k=0,1, \ldots
$$

(1) where: $x(n)$ - sampled signal uninterrupted; $X(k)$ rms of $\mathrm{k}$-harmonic of a particular signal $\mathrm{x}(\mathrm{t}) ; \mathrm{N}$ - number of samples per signal period; $\mathrm{n}$ - number of harmonics considered in the analysis; $\mathrm{k}, \mathrm{k}=2,3,4, \mathrm{n}$ - harmonic order.

The module from the (1) Fourier transform, determined according to dependencies, represents amplitude spectrum, while the angle represents phase spectrum.

The rules of measurement of harmonics and interharmonics currents and voltage are regulated by the norm [19], while the recommendations for averaging of measurement results in very short (3s), short (10min) and long $(2 \mathrm{~h})$ time were included in the norm [8]. When interharmonics occur in time waveform, precise determining of its spectrum is practically impossible, and it very often leads to a greater or lesser spectral blurring. [2, 4]. Spectral blurring causes that amplitudes of particular components are imprecisely determined, as a consequence the

University of Rzeszow, Faculty of Mathematics and Natural Sciences, Department of Computer Engineering, Pigonia 1, 35-310 Rzeszow, Poland, jbartman@ur.edu.pl 


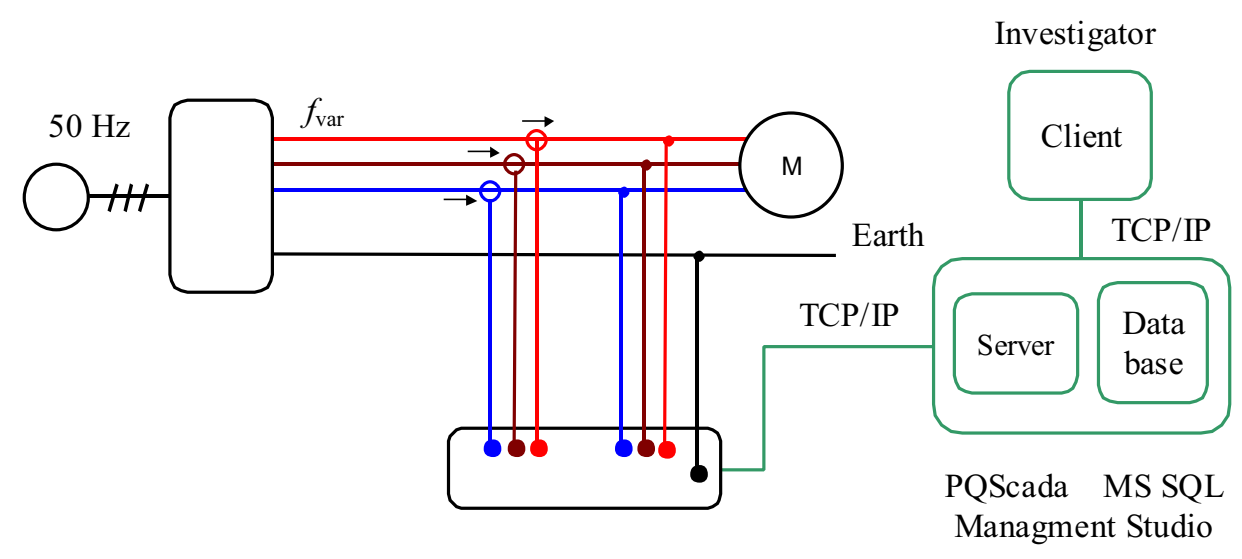

Fig. 1. Scheme of measuring system

power of harmonic at a determined frequency disperses onto the neighboring frequencies. The norm [19] suggests grouping of neighboring harmonics after being grouped, a demanded harmonic absorbs neighboring bars becoming their representation.

To assess the degree of periodic waveform distortion, multi criteria analysis needs to be used, applying rates that carry various information. The necessity of the assessment involves different influence of particular harmonics on working of network and machines. The paper involved examinations, next to the spectrum of harmonics and interharmonics, of THD harmonics content coefficient

$$
X_{T H D}=\frac{\sqrt{\sum_{k=2}^{n} X_{(k)}^{2}}}{X_{(1)}}
$$

(2) and the signal effective value (RMS).

$$
X_{R M S}=\sqrt{\frac{1}{T} \int_{t_{0}}^{t_{0}+T}[x(t)]^{2} d t}=\sqrt{\sum_{k=1}^{\infty} X_{(k)}^{2}}
$$

(3) where: $\mathrm{x}(\mathrm{t})$ - signal continuous; $\mathrm{X}(\mathrm{k})$ - rms of $\mathrm{k}$ harmonic of a particular signal $\mathrm{x}(\mathrm{t})$; XTHD - total harmonic distortion; XRMS - signal effective value; $\mathrm{n}$ - number of harmonics considered in the analysis; $\mathrm{k}, \mathrm{k}=2,3$, $4, \mathrm{n}$ - harmonic order; $\mathrm{m}$ - interharmonic order; $\mathrm{T}=1 / \mathrm{f1}$ period.

\section{Lab research area}

The research stand that is used for conducting measurements and analyses of output voltage distortion of frequency inverter consists of the following components: (Fig. 1):

Emerson Commander SK frequency inverter, $1.5 \mathrm{~kW}$ Temal 3Sg90L-4-IE2 induction motor, $1.5 \mathrm{~kW}$ Delta ECMA-E21315GS servomotor, Elspec Blackbox G4500 power quality analyzer, MS SQL server, Microcomputer with professional PQScada software and PQInvestigator dedicated to Elspec analyzer.
Induction motor is fed by frequency inverter which enables to adjust its rotational speed by changing power frequency. Commander SK performs control in in the open loop of reverse coupling in accordance with a sensorless, actual field vector orientation enabling full torque and speed control by an automatic compensation of torque and lost motion. The output signal is achieved by means of pulse width modulation method PWM [20]. Servomotor with adjustable torque and speed control is the motor load.

The measurements were conducted with the use of Elspec Blackbox G4500 microprocessor power quality analyzer. Elspec BlackBox G4500 is class A device that has been equipped with 11 measurement channels which allows simultaneous measurement of voltages and currents in each phase. In each period the voltage is sampled 1024 times which allows the analysis of up to 511 harmonic components. The current channels are sampled 256 times in a period, and the analysis of harmonics is possible up to as much as 127 th component. Moreover, the device allows the interharmonic analysis. The analyzer enables to register parameters of power quality in accordance with the EN 50160 and IEC 61000-4-15 norms [21].

The research stand has been arranged in such a way to enable easy execution of measurement of internal signals in the inverter-motor drive unit using the power quality analyzer. PQScada software enables to transfer measurement data from the analyzer to the database with MS SQL motor[22]. A complete analysis of data gathered in the system can be executed using dedicated PQInvestigator software. The application allows visualization and processing of gath-ered data, as well as creating discretionally tabulations [23].

\section{Results}

The measurements were conducted in the lab research area, the construction of which was described above. The investigation was carried out for a few various output frequencies of inverter supplying induction motor. The present paper involved the studies for the frequencies: 

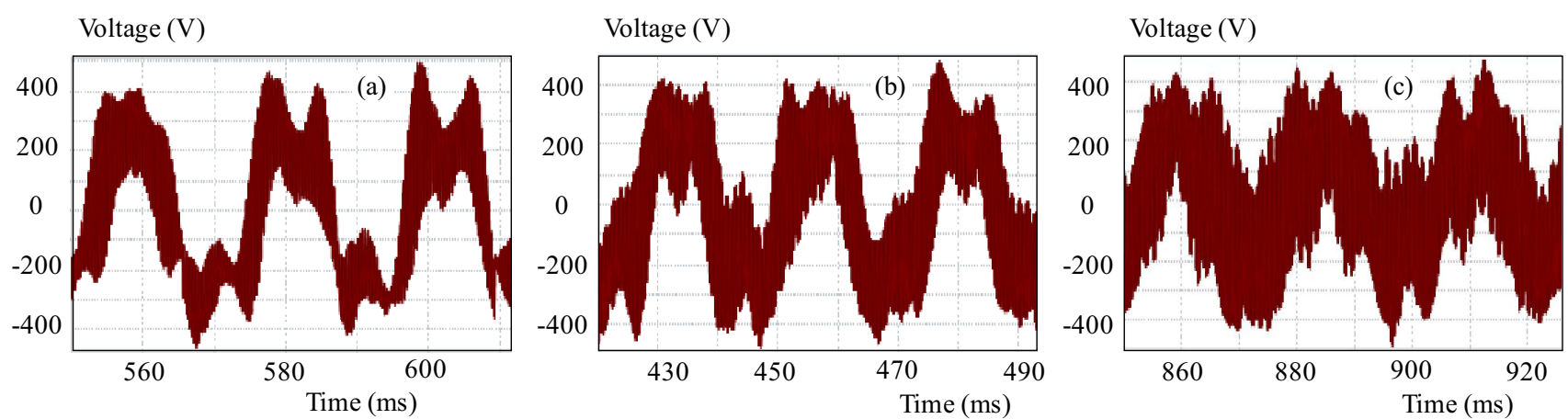

Fig. 2. Voltage waveform of frequency inverter for the frequencies of (a) $-f=45.8 \mathrm{~Hz},(\mathrm{~b})-42.5 \mathrm{~Hz},(\mathrm{c})-38.1 \mathrm{~Hz}$

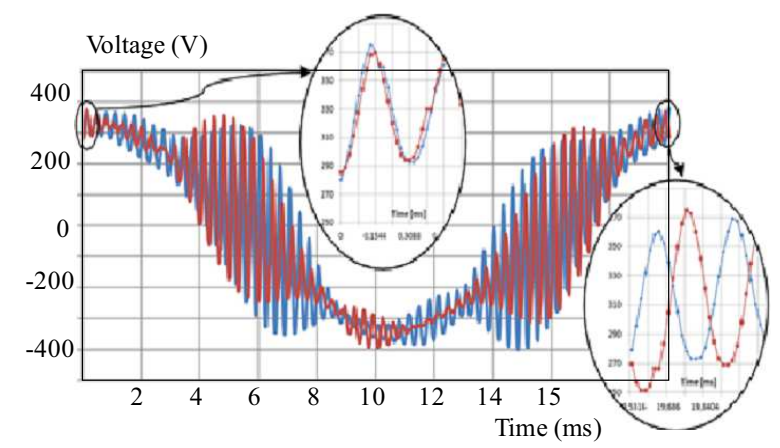

Fig. 3. The following two superposed periods of voltage waveform

$45.8 \mathrm{~Hz}, 42.5 \mathrm{~Hz}$ and $38.1 \mathrm{~Hz}$. Similar studies for the frequencies similar to network frequency $50 \mathrm{~Hz}$ were presented in the paper [5]. The studies of output voltage distortion of frequency inverter, presented in the paper, involve the analysis of: a. voltage waveform shape, b. particular harmonics and interharmonics content, c. variability of total harmonic distortion coefficient (THD), d. variability of effective voltage value on the output of inverter. The studies of voltage parameters listed in points b.-d., were conducted in three variants: analysis cycle by cycle taking into consideration all the components (dark blue color in the figures). in accordance with the PNEN 61000-4-30:2015 norm [7], analysis in time of 10 periods (red color in the figures), in accordance with the PN-EN 61000-4-30:2015 norm [7], value averaged in time of 150 periods (green color in the figures), The figures marked with the letter A concern the frequency $45.8 \mathrm{~Hz}$, B - $42.5 \mathrm{~Hz}, \mathrm{C}-38.1 \mathrm{~Hz}$.

\subsection{Voltage waveform shape}

Voltage waveform of frequency inverter was presented in fig. 2. The temporary values of output voltage show that amplitudes in particular periods differ, regardless of the output voltage of frequency inverter, which proves the signal to be nonstationary $[3,5,6]$. When comparing the figures $2 \mathrm{a}, 2 \mathrm{~b}$ and $2 \mathrm{c}$, it can be noted that the further to the bottom from $50 \mathrm{~Hz}$ the frequency is, the more the waveform becomes blurred. It results from greater involvement of components with frequencies different from the primary frequency (higher harmonics fig.5., interharmonics-fig.8.).
Direct comparison of the consecutive voltage periods was presented in fig. 3. The initial part and final part of a single period of signal were enlarged in order to enable easier observation. It can be easily observed that the waveforms not only have different amplitudes but there is also the time lag between them. The analysis can be complicated by such a character of signal waveform as it is difficult to determine where a single period starts and ends. It is caused by drifting of primary signal frequency and variable input of particular components in consecutive periods (Fig.5).It is confirmed that voltage waveform is nonstationary and quasiperiodic $[3,5,6]$.

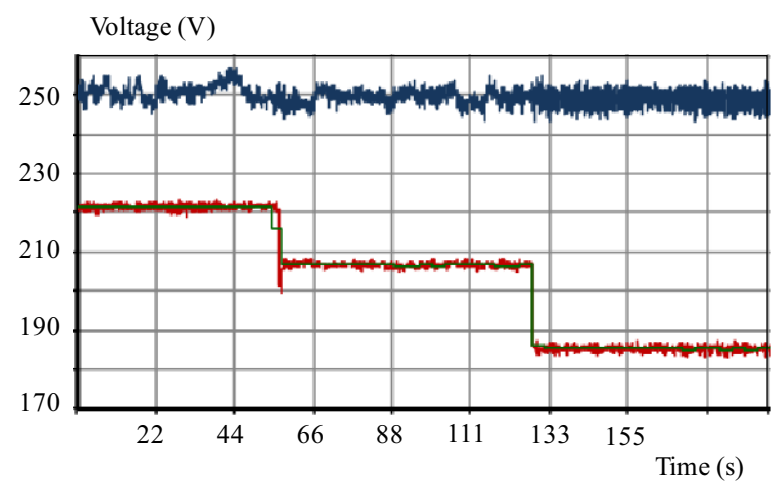

Fig. 4. Effective voltage (rms) of inverter: dark blue line cycle by cycle including all components, red line - analysis in window showing 10 periods in accordance with [7], green line value averaged within 150 periods in accordance with [7]

\subsection{Voltage effective value ( $\mathrm{rms}$ )}

The changes in voltage effective value in time and depending on the output frequency of frequency inverter were shown in fig. 4 . The most noteworthy aspect is a large ifference between effective voltage determined for the full spectrum (dark blue line) and effective voltage determined for the spectrum limited according to the norm [19] (green and red lines). For the three measured frequencies the trend is that the subject difference increases along with going away from the frequency of $50 \mathrm{~Hz}$. It is characteristic that voltage effective value determined from the full spectrum oscillates around one value (about 250V) while voltage value determined for the limited spectrum changes decreases along with going away from $50 \mathrm{~Hz}$. It 

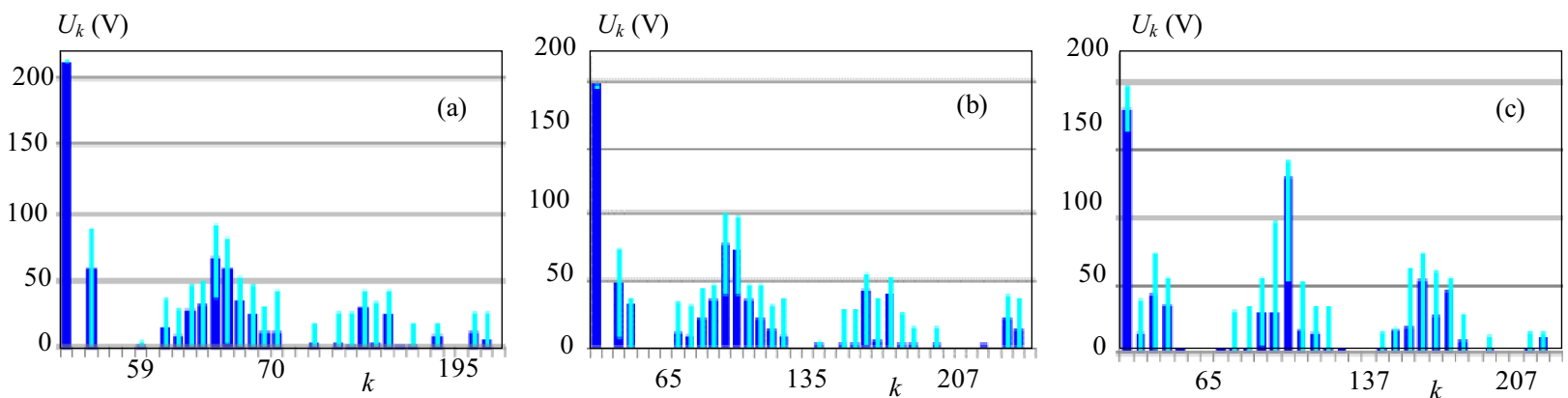

Fig. 5. Full spectrum of harmonics and fluxion of particular components.(limited to non-zero values).analysis cycle by cycle
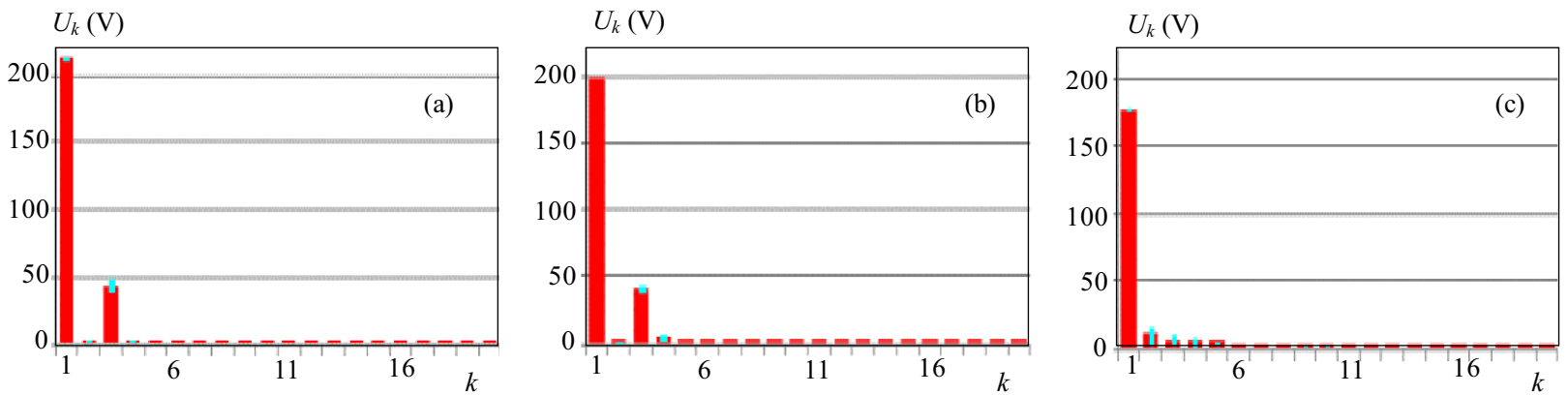

Fig. 6. Spectrum of voltage harmonics and fluxion of particular components (limited to 20 components). Analysis in window showing 10 periods in accordance with [7]. Red color harmonic value, blue color the range of its changes.
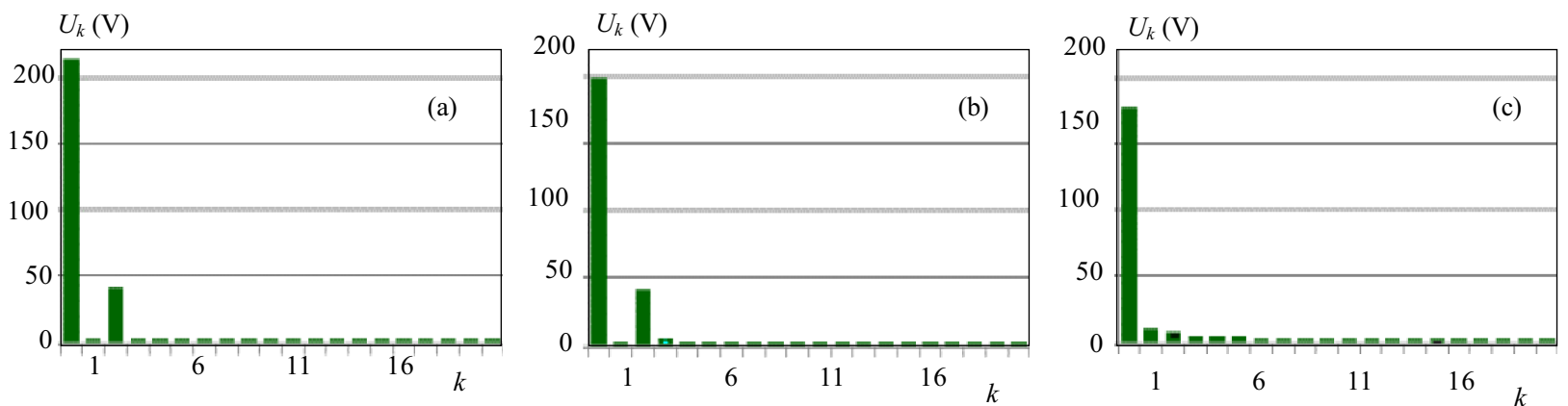

Fig. 7. Spectrum of voltage harmonics and fluxion of particular components (limited to 20 components). Analysis in window showing 150 periods in accordance with [7]. Green color harmonic value, blue color the range of its changes
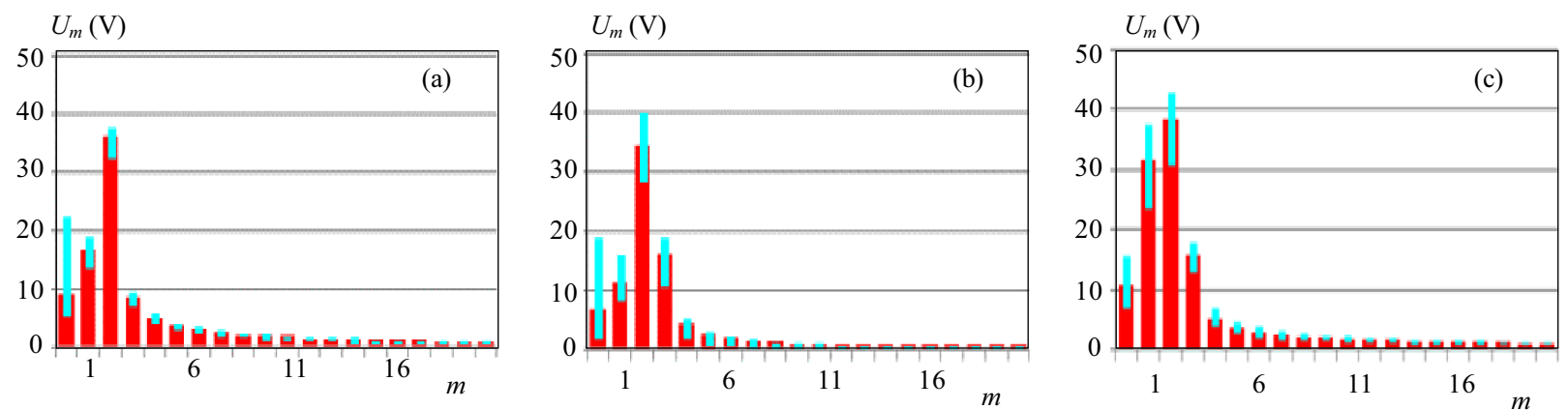

Fig. 8. Spectrum of voltage interharmonics and fluxion of particular components (limited to 20 components). analysis in window showing 10 periods in accordance with [7] . red color interharmonic value, blue color the range of its changes.
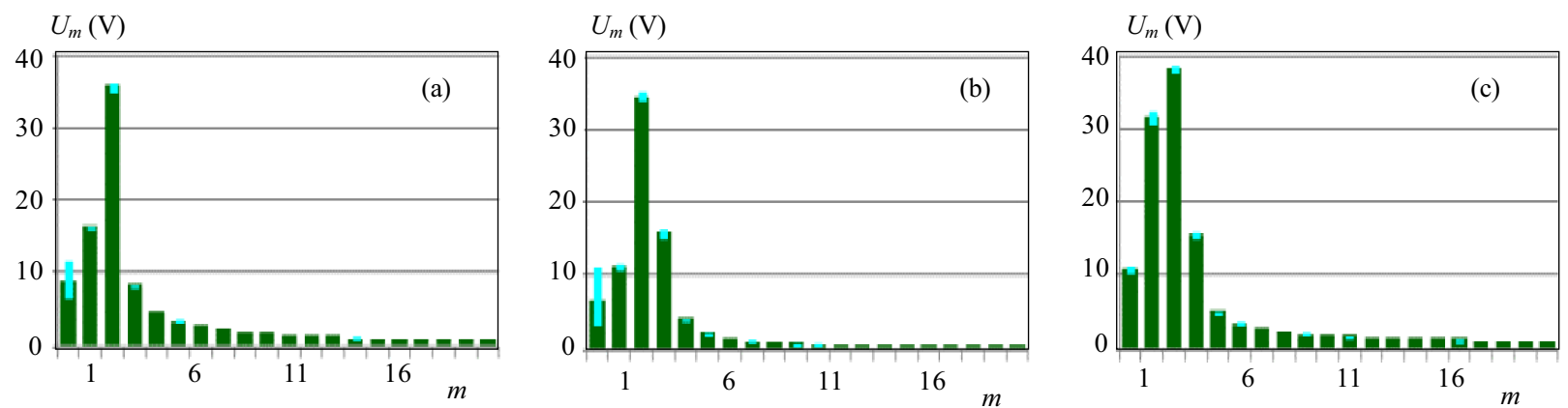

Fig. 9. Spectrum of voltage interharmonics and fluxion of particular components (limited to 20 components). analysis in window showing 150 periods in accordance with [7]. green color interharmonic value, blue color the range of its changes 


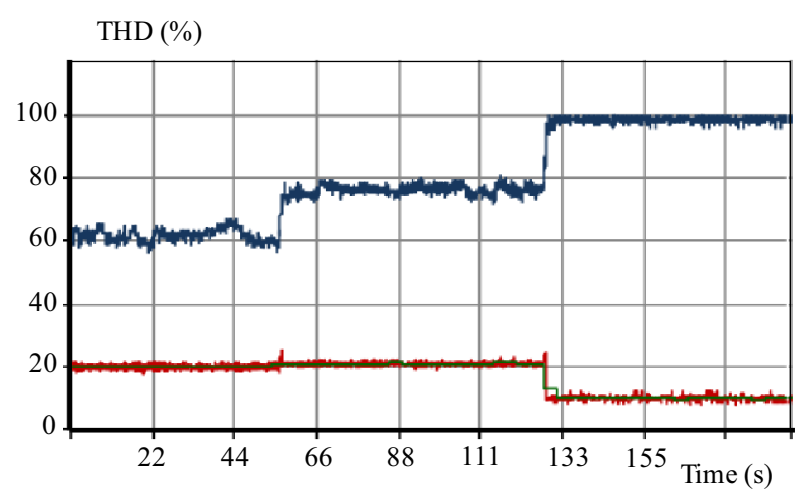

Fig. 10. Variability of Total Harmonic Distortion (THD) in time, for various inverter output. Dark blue line cycle by cycle including all components, red line - analysis in window showing 10 periods in accordance with [7], green line value averaged in time of 150 periods in accordance with [7].

is difficult to determine the dependence of voltage effective waveform on the time as its oscillation around the fixed value is chaotic. These oscillations decrease along with the increase of averaging time (blue line measurement cycle by cycle, green line value averaged from 150 periods).

\subsection{Harmonics content}

Figures 5 to 7 present the harmonics content in temporary waveforms of the output voltage of frequency inverter. When comparing the harmonics content for a particular output voltage frequency of inverter it is observed that with the increase of time for analysis, the values measured become steady (their dispersion decreases). The measurements done cycle by cycle indicate very high fluxion of harmonics irrespective of inverter output frequency (Fig.5.). The analyses performed in the window within 10 period time (Fig.6.) show that fluxion decreases, while the analyses averaged in 150 periods (Fig.7.) show that oscillations fail to occur. High oscillations of harmonics values calculated in particular periods (Fig.5.) are yet another evidence of signal non-stationarity, as it was noticed during discussion on the character of temporary waveforms. Identical observation can be found in the works where similar issues are discussed $[3,5,6]$. The fact that averaging of harmonics values in longer time interval levels their oscillations (Fig.7), provides evidence for certain signal regularity.

\subsection{Interharmonics content}

The interharmonics content in the waveforms of temporary voltages were presented in fig. 8 and fig. 9 , with averaging in 10 periods and in 150 periods respectively. In both figures the attention is drawn to the high value of interharmonics of low row irrespective of inverter output frequency. Although the spectrum for each output frequency is slightly different, in all cases investigated the third interharmonic reaches the value higher than $30 \mathrm{~V}$, and neighboring interharmonics around a dozen or so volt. Therefore, if the distortion analysis is limited only to the spectrum of harmonics, it will cause that information, which is important from operating point of view, concerning the components of sub-harmonics will be lost.

In the spectrum of interharmonics, the attention is drawn to high fluxion of component amplitudes for consecutive measuring times. For the analysis of time equal to 10 waveform periods, the differences between extreme values of amplitudes are comparable to the everage determined value (Fig.8.). Ths effect is certainly caused by signal nonstationarity $[3,5,6]$, but it may be also caused partly by imperfections of the method applied in the analysis [6]. The studies which average the value in 150 periods (Fig.8) show that fluxion in values of amplitudes for particular measuring times are lower, but still important (especially for the first interharmonc).

\subsection{THD value}

Figure 10 presents the fluxion in total harmonic distortion (THD) in time, for various output frequencies of inverter. It is difficult to determine variation in time it is probably quasi-stochastic. In contrast, the evaluation of THD depending on the frequency clearly shows that if the analysis is limited to 50 harmonics, as suggested by the norm [19], it may lead wrong conclusions. Fig. 10 presents the curve representing the THD value, determined in accordance to the norm [19] (for 10 periods red line and 150 periods green line) for the frequencies of $45.8 \mathrm{~Hz}$ and for $42.5 \mathrm{~Hz}$ indicate a steady value, while for $38,1 \mathrm{~Hz}$ the value of THD even decreases. The measurement of THD covering the whole spectrum (dark blue line) shows that, in fact, when the frequency decreases, THD significantly increases. Moreover, the value of full THD is significantly higher when compared to the value determined according to the norm [19], that is consistent with the analysis of full spectrum of harmonics discussed above (Fig.5.)

\section{Conclusion}

The conducted studies concern the analysis of the character of output voltage waveform of frequency inverter fed induction motor. They confirmed the fact described in the literature that the analyzed voltage is distorted $[2,3,4]$. What is more, the studies unequivocally demonstrated that the voltage signal generated by the frequency inverter is nonstationary $[3,5,6]$. As it was assumed in the first part of the present thesis that regardless of nonstationarity, the voltage is rather regular, was confirmed by the results of the studies. Therefore, it seems to be right to define the output voltage of frequency inverter as quasiperiodic or almost periodic waveform $[3$, $5,6]$.

The norm [19] ordered by IEC related to measurements of power quality can not be a basis for the the evaluation of signal distortion in real time. It is caused by the limited spectral analysis of the signal up to 50 
harmonics. The analysis demonstared that such a limitation can lead to huge underestimations of the degree of waveform distortion. This observation is consistent with the conclusions included in this paper [4].

The values of interharmonics of low row, regardless of the output voltage of frequency inverter, are relatively high - of around several dozen volt. If the analysis is limited only to the harmonics, the information, important from an operating point of view, concerning the components of subharmonics will be lost. The obtained results show that the measurements of voltage effective value are ambiguous. The measurements limited to 50 harmonics (according to the norm [19]) indicate a significantly lower voltage effect value than the measurements that involve the spectrum of 511 harmonics. Moreover, the short-term measurements (10 periods, cycle by cycle) show high fluxion in voltage values in time, which disappears in longer measurements (150 periods).

\section{REFERENCES}

[1] T. Binkowski, "Universal high speed induction motor driver", Lecture Notes Electrical Engineering, Springer Verlag 2015, pp. 149-162.

[2] Z. Hanzelka and A. Bień, "Harmonics, Interharmonics", Power Quality Application Guide, 4.

[3] J. Rezmer, Z. Leonowicz and R. Gono, "Analysis of distorted waveform power converete systems", Przegld Elektrotechniczny $87,1,2011$, pp. 254-257.

[4] J. Bartman, "Accuracy of reflecting the waveforms of current and voltage through their spectrum determined by the standards regulating measurements", Revue Roumaine des sciences techniques - Serie Electrotechnique et Energetique, vol. 61, no. 4 pp.355-360.

[5] J. Bartman and D. Sobczyński, "The analysis of the voltage and current waveforms of frequency inverter fed induction motor", Computing Science and Technology, 2016, pp. 5-18.

[6] B. M. Antić, Z. L. Mitrović and V. V. Vujičić, "A Method for Harmonic Measurement of Real Power Grid Signals with Frequency Drift using Instruments with Internally Generated Reference Frequency", Measurement Science Review, vol. 12, no.6, 2012, pp. 277-285.

[7] H. C. Lin, "Power harmonics and interharmonics measurment using Recursive Group-Harmonic Power Minimizing Algorithm", IEEE Transactions on Industrial Electronics, 59, 2, pp 1184-1193, 2012.

[8] IEC61000-4-30, Electromagnetic and compatibility, "Testing and measurement techniques: Current quality measurement methods".

[9] J. Leszczyński, "Badanie jakości energii elektrycznej: analiza porównawcza metod i przepisów ", Prace Naukowe Instytutu Maszyn, Napdów i Pomiarów Elektrycznych Politechniki Wrocławskiej.Studia i Materiały, 30, pp. 520-534, 2010, (in Polish).

[10] A. Koziorowska, K. Kuryło and J. Bartman, "Harmoniczne napiecia i pradu generowane przez nowoczesne napedy stosowane w kopalniach kruszywa", Przeglad Elektrotechniczny, 06, 2010, pp. 279-284 (in Polish).

11] J. Bartman, A. Koziorowska, K. Kuryło and W. Malska, "Analiza rzeczywistych parametrów sygnałów elektrycznych zasilajcych układy napedowe pomp wodociagowych", Przeglad Elektrotechniczny, 08, 2011, pp.8-11 (in Polish).

12] A. Koziorowska and J. Bartman, "Wpływ kompensacji mocy biernej na zawartość harmonicznych na przykładzie urzadzeń kopalnianych", Przeglad Elektrotechniczny, 01, 2014, pp 136-140 (in Polish).

13] P. Otomański and G. Wilczyński, "The application of programmable AC source to generation of higher harmonics examination of current quality", Przeglad Elektrotechniczny, 2015, 8, pp 38-41.2015 (in Polish).

14] P. Gnaciński and M. Pepliński, "Induction cage machine supplied with voltage containing subharmonics and interharmonics", IET Electric Power Applications 8, pp. 287-295, 2014.

15] S. R. Kathalingam and P. Karantharaj, "Comparison Of Multiple Carrier Disposition PWM Techniques Applied For MultiLevel Shunt Active Filter", Journal of Electrical Engineering, vol. 63, no.4, 2012, pp. 261265.

[16] P. Petković and D. Stevanović, "Detection Of Power Grid Harmonic Pollution Sources Based On Upgraded Power Meters", Journal of Electrical Engineering, 65, 3, 163168, 2014.

[17] J. Zygarlicki and J. Mroczka, "Prony's method with reduced sampling - numerical aspects", Metrology and Measurement Systems, vol. XXI, no. 3, pp. 521534, 2014.

[18] I. Taranenko, R. Pawełek and O. Gorpynych, "Zastosowanie transformaty falkowej do analizy przebiegów napieć zasilajacych napedy z czestotliwościowa regulacja predkości obrotowej", Przeglad Elektrotechniczny, 91, No 11, pp. 69-73, 2015 (in Polish).

[19] IEC 61000-4-7, Testing, and and measurement and techniques, "General guide for harmonics and interharmonics measurements and instrumentations for current supply systems",.

[20] "Advanced User Guide Commander SK" (2015), http://www.emersonindustrial.com.

[21] "User and Installation Guide G4500/G3500 Black Box Portable Power Quality Analyzer", (2014), http://www.elspec-ltd.com.

[22] "User Manual PQScada v4. 2. 2. 2." (2014), http://www.elspec-ltd.com.

[23] "Investigator version 2. 3. User Manual" (2014), http://www.elspec-ltd.com.

[24] "Investigator version 2. 3. User Manual" (2014) http://www.elspec-ltd.com.

Received 23 May 2016

Jacek Bartman, (Ing, PhD) was born in Eańcut, Poland in 1965. He graduated from the Faculty of Electrical Engineering, Rzeszow University of Technology, in 1989. In 1999 received the $\mathrm{PhD}$ degree in AGH University Science and Technology in Krakow. In 1989 he joined the staff of the Institute of Technology in WSP Rzeszow. His research interests include: measurement and analysis of deformed waveforms and the application of mathematics and computer science in technical sciences in particular mathematical modeling and artificial neural networks. 